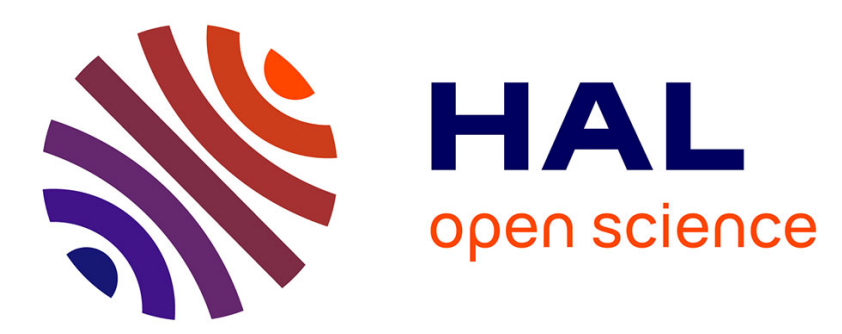

\title{
Liver cell polyploidization: a pivotal role for binuclear hepatocytes
}

J.E. Guidotti, O. Brégerie, A. Robert, P. Debey, C. Brechot, C. Desdouets

\section{To cite this version:}

J.E. Guidotti, O. Brégerie, A. Robert, P. Debey, C. Brechot, et al.. Liver cell polyploidization: a pivotal role for binuclear hepatocytes. Journal of Biological Chemistry, 2003, 278 (21), pp.19095-19101. hal-02679584

\section{HAL Id: hal-02679584 \\ https://hal.inrae.fr/hal-02679584}

Submitted on 31 May 2020

HAL is a multi-disciplinary open access archive for the deposit and dissemination of scientific research documents, whether they are published or not. The documents may come from teaching and research institutions in France or abroad, or from public or private research centers.
L'archive ouverte pluridisciplinaire HAL, est destinée au dépôt et à la diffusion de documents scientifiques de niveau recherche, publiés ou non, émanant des établissements d'enseignement et de recherche français ou étrangers, des laboratoires publics ou privés. 


\title{
Liver Cell Polyploidization: A Pivotal Role for Binuclear Hepatocytes*婳
}

Received for publication, January 29, 2003, and in revised form, March 6, 2003 Published, JBC Papers in Press, March 7, 2003, DOI 10.1074/jbc.M300982200

\author{
Jacques-Emmanuel Guidottił§, Olivier Brégerieł\$, Aude Robertł, Pascale Debeyl, \\ Christian Brechot $\ddagger$, and Chantal Desdouets $\ddagger$ \\ From $\ddagger I N S E R M$ U370, CHU Necker, 156 Rue de Vaugirard, 75015 Paris, France and 1 Unité Mixte de Recherche 8646 \\ CNRS-MNHN, U565 INSERM, Muséum National d'Histoire Naturelle, 53 Rue Buffon, 75005 Paris, France
}

\begin{abstract}
Polyploidy is a general physiological process indicative of terminal differentiation. During liver growth, this process generates the appearance of tetraploid (4n) and octoploid (8n) hepatocytes with one or two nuclei. The onset of polyploidy in the liver has been recognized for quite some time; however, the cellular mechanisms that govern it remain unknown. In this report, we observed the sequential appearance during liver growth of binuclear diploid $(2 \times 2 n)$ and mononuclear $4 n$ hepatocytes from a diploid hepatocyte population. To identify the cell cycle modifications involved in hepatocyte polyploidization, mitosis was then monitored in primary cultures of rat hepatocytes. Twenty percent of mononuclear $2 \mathrm{n}$ hepatocytes failed to undergo cytokinesis with no observable contractile movement of the ring. This process led to the formation of binuclear $2 \times 2 \mathrm{n}$ hepatocytes. This tetraploid condition following cleavage failure did not activate the p53-dependent checkpoint in $G_{1}$. In fact, binuclear hepatocytes were able to proceed through $S$ phase, and the formation of a bipolar spindle during mitosis constituted the key step leading to the genesis of two mononuclear $4 n$ hepatocytes. Finally, we studied the duplication and clustering of centrosomes in the binuclear hepatocyte. These cells exhibited two centrosomes in $G_{1}$ that were duplicated during $S$ phase and then clustered by pairs at opposite poles of the cell during metaphase. This event led only to mononuclear $4 \mathrm{n}$ progeny and maintained the tetraploidy status of hepatocytes.
\end{abstract}

Polyploidy is a general physiological process that prevails in many cellular systems including plants, insects, and mammals (1). The onset of cellular polyploidization is associated with late fetal development and postnatal maturation. Advanced polyploidy in mammalian cells is indicative of terminal differentiation and senescence (2). Hepatocytes come under the former category. During growth, the liver parenchyma undergoes dramatic changes characterized by gradual polyploidization during which hepatocytes of several ploidy classes emerge as a result of modified cell division cycles. This process generates the successive appearance of tetraploid and octoploid cell classes with one or two nuclei. Thus, in the liver of a newborn

* This study was supported by grants from INSERM and the Ligue Nationale Contre le Cancer. The costs of publication of this article were defrayed in part by the payment of page charges. This article must therefore be hereby marked "advertisement" in accordance with 18 U.S.C. Section 1734 solely to indicate this fact.

S The on-line version of this article (available at http://www.jbc.org) contains three videos depicting cell mitosis (Videos 1-3).

$\S$ These authors contributed equally to this work.

$\|$ To whom correspondence should be addressed. Tel.: 33-1-40615545; Fax: 33-1-40-615581; E-mail: desdouet@necker.fr. rat, hepatocytes are exclusively diploid $(2 \mathrm{n}),{ }^{1}$ and polyploidization starts after weaning. In adult rats, about $10 \%$ of hepatocytes are diploid, $70 \%$ are tetraploid, and $20 \%$ octoploid. If we consider the polyploid fraction, $20-30 \%$ of hepatocytes are binuclear (either $2 \times 2 \mathrm{n}$ or $2 \times 4 \mathrm{n})(3,4)$. The degree of polyploidization varies among mammals (5) and particularly in humans, where the number of polyploid cells averages $20-30 \%$ in the adult liver $(6,7)$. Interestingly, in different liver pathologies, hepatocarcinoma for example, hepatocellular growth shifts to a nonpolyploidizing growth pattern, and expansion of the diploid hepatocyte population has been found to take place $(4,7)$.

Polyploidization is a general strategy of cell growth that enables an increase in metabolic output, cell mass, and cell size, and may constitute an alternative to cell division (1). In addition, the status of ploidy is likely to affect the expression profile of specific genes, as has been described in a yeast system (8). The biological significance of hepatic polyploidy remains unclear. It has been suggested that the polyploid genome may provide protection against the dominant expression of mutated oncogenes, a safety measure that might be helpful for an organ heavily engaged in drug detoxification (9).

The onset of polyploidy in the liver has been recognized for quite some time. However, the cellular mechanisms that govern the passage from mononuclear $2 n$ to binuclear $2 \times 2 n$ and/or mononuclear $4 \mathrm{n}$ hepatocytes remain unknown. One possible explanation is that binuclear $2 \times 2$ n hepatocytes may play a pivotal role in the genesis of mononuclear $4 \mathrm{n}$ hepatocytes. Hepatocyte binucleation results from either a defect in the cytokinesis of mononuclear $2 \mathrm{n}$ cells $(3,7)$ or the fusion of two mononuclear $2 \mathrm{n}$ cells (10). Thereafter, binuclear $2 \times 2 \mathrm{n}$ hepatocytes may divide, leading to the genesis of two daughter mononuclear $4 \mathrm{n}$ hepatocytes. A mononuclear $4 \mathrm{n}$ hepatocyte then embarks upon a new round of binucleation/polyploidization with the formation of $2 \times 4 \mathrm{n}$ and $8 \mathrm{n}$ cells. An alternative explanation for liver polyploidization is that a mononuclear $2 \mathrm{n}$ hepatocyte gives rise directly to mononuclear $4 \mathrm{n}$ cells through endoreplication. This process has already been described in plants, Drosophila, and mammals, notably in megakaryocyte and trophoblast cells, and results from uncoupling of the normal link between $\mathrm{S}$ phase and mitosis (1). In murine models exhibiting an absence or deregulated expression of genes such as $p 21$, S-phase kinase associated protein 2 (Skp2), and excision repair cross-complementing protein 1 (ERCC1), endoreplication induces premature liver polyploidization. In these mice, the liver has been characterized by an increase in the number of mononuclear polyploid fractions (11-13).

The aim of this work was to define the cellular mechanisms

${ }^{1}$ The abbreviations used are: $2 \mathrm{n}$, diploid; $4 \mathrm{n}$, tetraploid; $8 \mathrm{n}$, octaploid; $2 \times 2$ n (or $2 \times 4 \mathrm{n})$, binuclear; BrdUrd, 5-bromo-2'-deoxyuridine. 
involved in liver polyploidization by studying the hepatocyte cell cycle. We demonstrated that the binuclear hepatocyte is central to the polyploidization process. Having characterized the in vivo kinetic of liver polyploidization, we showed that the abortion of cytokinesis induced the formation of binuclear hepatocytes. This tetraploid condition following cleavage failure did not activate the p53-dependent checkpoint in $\mathrm{G}_{1}$; binuclear cells could divide and generate two mononuclear $4 \mathrm{n}$ daughter cells. This event was driven by the clustering of two centrosomes at each pole of the cell, leading to the formation of a bipolar spindle.

\section{EXPERIMENTAL PROCEDURES}

Animals-Male Wistar rats (Iffacredo, Lyon, France) were treated in accordance with European Union regulations on animal care. The rats were housed under standard light/dark conditions and received pelleted food and water ad libitum. All rats were weaned 17 days after birth (weaning and the commencement of feeding influence hepatic polyploidy) (5).

In Situ Detection of Ploidy-Liver tissues were fixed in 10\% phosphate-buffered formalin and then embedded in paraffin. Three-micrometer-thick tissue sections were deparaffinized in xylene and, after rehydration, boiled for $3 \times 5 \mathrm{~min}$ in $10 \mathrm{mmol} /$ liter citrate buffer, $\mathrm{pH} 6.2$, in a microwave oven. Immunohistochemistry was performed as described below. Plasma membranes were labeled with anti- $\beta$-catenin antibody (diluted 1:50, BD Transduction Laboratories). Hoechst $33342(0.2 \mu \mathrm{g} /$ $\mathrm{ml}$ ) was used to stain and quantify DNA in each nucleus. Tissue sections were analyzed under a Zeiss (Axiovert 35) (Carl Zeiss, Gottingen, Germany) inverted microscope equipped for epi-illumination. Zeiss Plan Neofluar $40 \times$ objectives (numerical aperture, 0.75 ) were chosen that enabled the collection of light from the entire thickness of the nucleus, these conditions being essential for adequate DNA content determinations. Images were captured using a cooled CCD camera (Photometrics, Tucson, Arizona; KAF 1400-G2, class 2) on 4056 gray levels. Automatic quantitative image analysis was performed in 12 bits using IPLab Spectrum software. Nuclei were assigned as mono or binucleated hepatocytes by comparing fluorescent and membrane-labeling images. Other liver cell types (defined by their morphological characteristics), overlapping nuclei, or debris were eliminated interactively. Parameters such as integrated fluorescence intensity (IntF) were stored in computer files for analysis using the KaleidaGraph and Imastat software (Imastat as developed by P. Debey) (14). A minimum of 300 hepatocytes were studied and observed on eight to twelve separate fields; these observations concerned specimens from four animals for each point analyzed. This number of hepatocytes was within the range covered by other imaging-based studies.

Live Cell Videomicroscopy and Immunofluorescence Microscopy on Primary Rat Hepatocytes-Primary rat hepatocytes were isolated by liver perfusion with a collagenase blend (Liberase, Roche Applied Science). After isolation, cells were collected in William's medium E enriched with $1 \mathrm{mg} / \mathrm{ml}$ bovine serum albumin and left to sediment for 20 $\mathrm{min}$. After three centrifugations $(65 \times g$ for $1 \mathrm{~min})$, hepatocytes were seeded at $5 \times 10^{5}$ cells $/ \mathrm{cm}^{2}$ on plastic dishes in William's medium $\mathrm{E}$, supplemented with $10 \%$ fetal bovine serum, $1 \mathrm{mg} / \mathrm{ml}$ bovine serum albumin, and $5 \mu \mathrm{g} / \mathrm{ml}$ bovine insulin in a $37{ }^{\circ} \mathrm{C}$ incubator with $5 \% \mathrm{CO}_{2}$ atmosphere. All culture medium used contained penicillin (100 units/ $\mathrm{ml})$, streptomycin $(100 \mu \mathrm{g} / \mathrm{ml})$, and fungizone $(250 \mathrm{ng} / \mathrm{ml})$. Hepatocyte viability was assessed to be $>90 \%$ using trypan blue dye exclusion. After cell attachment ( $4 \mathrm{~h}$ later), the medium was removed and replaced by fresh serum-free William's medium E containing $0.5 \mathrm{mg} / \mathrm{ml}$ bovine serum albumin, $5 \mu \mathrm{g} / \mathrm{ml}$ bovine insulin, and $710^{-7} \mathrm{M}$ hydrocortisone hemisuccinate. The medium was changed every day thereafter. Twenty-four $\mathrm{h}$ after plating, the cells were placed in the mitogenic stimulation medium, i.e. the same medium describe above supplemented with epidermal growth factor (EGF) at $50 \mathrm{ng} / \mathrm{ml}$ and pyruvate at $20 \mathrm{~mm}$ (mitogenic stimulation medium). This medium was used throughout the culture time. Under these conditions, maximal DNA synthesis occurs from $48-60 \mathrm{~h}$, depending on the cell culture (15).

For live cell microscopy, hepatocytes were grown on $35 \times 10$-mm tissue culture plates and mounted on the microscope after $48 \mathrm{~h}$ of culture. During imaging, hepatocytes were maintained in William's medium $\mathrm{E}$ on a stage heated at $37^{\circ} \mathrm{C}$ under a $5 \% \mathrm{CO}_{2}$ atmosphere. Cells were imaged at $3 \mathrm{~min}$ intervals for $24 \mathrm{~h}$ with a Leica DMIRBE using a $63 \times$ lens (numerical aperture, 0.7 ), a condenser (working distance, 23 $\mathrm{mm}$; numerical aperture, 0.53 ), and a Pentamax cooled CCD camera (Popper Scientific) coupled to an electronic shutter. Metamorph 4.6 was used for computer-based image acquisition and analysis of live cell data. The single images shown were prepared using Adobe Photoshop ${ }^{\circledR}$ 5.5.

For immunofluorescence microscopy, hepatocytes were grown on chambered coverslips and fixed with methanol at $-20^{\circ} \mathrm{C}$ for $10 \mathrm{~min}$. The coverslips were then washed and blocked with the Biotin blocking system (Dako). Incubations with primary mouse antibodies (anti- $\gamma-$ tubulin (1:200, GTU88, Sigma), anti- $\beta$-tubulin (1:200, TUB2.1, Sigma), and anti-p53 (1:100, FL-393, Santa Cruz Biotechnology)) were carried out for $1 \mathrm{~h}$ at room temperature. For the detection of primary antibodies, biotinylated swine anti-mouse or anti-rabbit immunoglobulin solutions were used (1:200, Dako) followed by FITC-conjugated streptavidin $(1: 200$, DAKO). Hoechst $33342(0.2 \mu \mathrm{g} / \mathrm{ml})$ was included in the final incubation to stain DNA.

Western Blot Analyzes-Hepatocyte protein extracts were prepared in lysis buffer containing $50 \mathrm{~mm}$ Tris, pH 7.5, $250 \mathrm{~mm} \mathrm{NaCl}, 2 \mathrm{~mm}$ EDTA, 0.5\% Nonidet P-40, $50 \mathrm{~mm} \mathrm{NaF}, 0.1 \mathrm{~mm}$ Na3VO4, $1 \mathrm{~mm}$ dithiothreitol, $1 \mathrm{~mm}$ phenylmethylsulfonyl fluoride, and $2 \mu \mathrm{g} / \mathrm{ml}$ leupeptin, pepstatin, and aprotinin. Protein concentration was determined by the Bradford method (Bio-Rad); $30 \mu \mathrm{g}$ of protein were fractionated on SDSPAGE and then transferred to Hybond C membrane (Amersham Biosciences). p53, cyclin $\mathrm{E}$, and $\beta$-tubulin proteins were detected using specific antisera (FL-393 against p53 and M20 against cyclin E with incubation overnight at $4{ }^{\circ} \mathrm{C}$; both antisera were from Santa Cruz Biotechnology). Horseradish peroxidase-conjugated antibody (Amersham Biosciences) was used as second antibody (dilution 1:2000, incubation for $1 \mathrm{~h}$ at room temperature). Immunoreactive bands were visualized with enhanced chemiluminescence (ECL, Amersham Biosciences) according to the manufacturer's instructions.

5-Bromo-2'-deoxyuridine (BRD) Labeling-The percentage of cells undergoing DNA synthesis was estimated by counting the number of BrdUrd-labeled cells using the BrdUrd detection kit II (Roche Applied Science). Cells were incubated with BrdUrd labeling medium for $12 \mathrm{~h}$. The medium was then removed and the cells were fixed in ethanol/ acetic acid (70:30) and stained according to manufacturer's instructions. Ten separate fields were counted per plate, and averages were representative of three independent experiments.

\section{RESULTS}

Kinetics of Polyploidization during Liver Growth-Although several studies have described changes in ploidy at various stages of liver development, none has established the in vivo emergence of tetraploid hepatocytes (binuclear $2 \times 2 \mathrm{n}$ or mononuclear $4 \mathrm{n}$ cells). For this purpose, we used an approach based on quantitative fluorescence imaging (14). The simultaneous nuclear and plasma membrane labeling of liver tissue sections made it possible to determine the number of nuclei per cell (Fig. $1 A$ ) and thus calculate the binuclear hepatocyte fraction (Fig. $1 C$ ). The use of a stoichiometric DNA labeling agent, Hoechst 33342 , enabled determination of the DNA content in all cells by measuring the integrated fluorescence emitted by each nucleus. A typical histogram of integrated fluorescence values for mononuclear cells is shown in Fig. $1 B$. Because of the clear bimodal distribution around two main values separated by a factor of 2 , the distribution of $2 \mathrm{n}$ and $4 \mathrm{n}$ mononuclear hepatocytes was assessed with accuracy even in a small number of nuclei. Using this technique, we examined the hepatic ploidy status of 12-39-day-old rats. The relative proportions of different hepatocyte ploidy classes during liver development are shown in Fig. 1C. We found that hepatocytes were mostly diploid in the livers of young rats (99\% at day 12). From day 22 the proportion of diploid cells started to fall significantly, with the successive appearance of binuclear $2 \times 2 \mathrm{n}$ and mononuclear $4 \mathrm{n}$ hepatocytes. Binuclear $2 \times 2 \mathrm{n}$ cells were first detected at day 22 (4.6\% of hepatocytes), and then their proportion rose rapidly between days 25 and 30 to reach $27.5 \%$ of the total hepatocyte population (Fig. $1 C$ ). The relative proportion of the binuclear population decreased gradually and comprised only $2 \times 2$ n DNA content until at least day 39 (data not shown). The mononuclear $4 \mathrm{n}$ hepatocyte population was only present at significant levels 25 days after birth and represented $5.2 \%$ of the total hepatocyte population. Up to day 25 , the fraction of 
A

FIG. 1. In situ analysis of hepatocyte polyploidy during liver growth. $A$, imaging of a liver section after double staining with Hoechst (nuclear labeling, blue) and $\beta$-catenin (plasma membrane labeling, green) enabled a distinction between mononuclear and binuclear hepatocytes. $B$, representative histogram of the DNA content distribution of mononuclear hepatocytes from a 35-day-old rat. DNA content was evaluated by recording the Hoechst-integrated fluorescence in each nucleus. Integrated fluorescence is expressed in arbitrary units. The first peak is representative of hepatocytes with $2 \mathrm{n}$ DNA content. The second peak is positioned at twice the value of the first peak and is representative of hepatocytes with 4n DNA content. $C$, polyploidization during liver growth. At each point, four rats were independently analyzed. Percentages of mononuclear $2 \mathrm{n}(\bullet)$, binuclear $2 \times 2 \mathrm{n}(\mathbf{\square})$, and mononuclear $4 \mathrm{n}(\mathbf{\Lambda})$ cells were calculated as described under "Experimental Procedures." The average percentage of each population is shown on the curve. S. E. values were in all cases below $10 \%$.
B
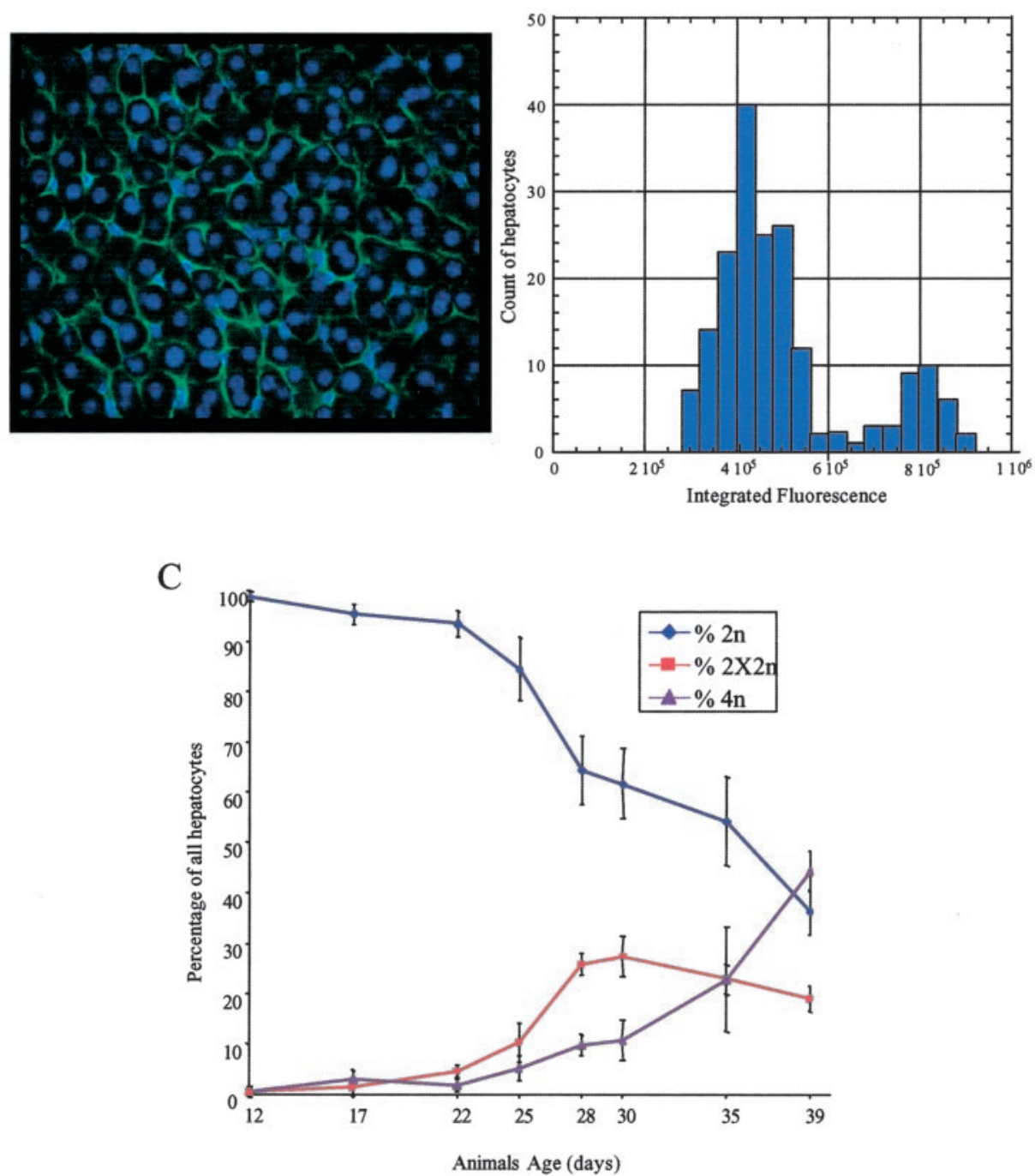

nuclei with a 4 n DNA content represented only cycling mononuclear $2 \mathrm{n}$ cells in $\mathrm{G}_{2}$, as determined by the percentage of replicating nuclei in control rats injected with BrdUrd (data not shown and Ref. 16). These cells were not present at significant levels after 25 days. At day 30, a sharp increase was observed in the number of mononuclear $4 \mathrm{n}$ hepatocytes $(10.9 \%$ of the total population), and this hepatocyte population was in the majority at day 39 , reaching $44.4 \%$ of the total population (Fig. 1C). These results clearly demonstrated in vivo that binuclear $2 \times 2 \mathrm{n}$ and mononuclear $4 \mathrm{n}$ hepatocytes appear successively during liver growth.

Genesis of Binuclear Hepatocytes and Abortion of Cytokinesis-To define the genesis of binuclear hepatocytes, we monitored the division of hepatocytes isolated from 24-day-old rats corresponding to the moment of appearance of these cells in vivo. After $48 \mathrm{~h}$ of culture, mononuclear $2 \mathrm{n}$ hepatocytes were observed for $24 \mathrm{~h}$ to visualize their passage through mitosis; during this period, $60 \%$ of mononuclear $2 \mathrm{n}$ hepatocytes were in $\mathrm{S}$ phase or had already proceeded through this phase (BrdUrd labeling, data not shown). At least 50 mononuclear $2 \mathrm{n}$ hepatocytes were inspected during four independent experiments, and no morphological evidence of cell apoptosis was observed at any time during the study. In $80 \%$ of the mononuclear $2 \mathrm{n}$ hepatocytes analyzed division was normal (example on Fig. $2 A$ and on Video 1), the cell initiated prophase, and the chromosome then lined up along the metaphase plate (Fig. 2A, panel 2). Cells then pinched off in the middle during telophase/cytokinesis (Fig. 2A, panel 3). Once mitosis was complete, the resulting two daughter mononuclear $2 \mathrm{n}$ hepatocytes became individualized (Fig. $2 A$, panel 4 ). In contrast, $20 \%$ of the mononuclear $2 \mathrm{n}$ cells observed exited from mitosis inappropriately (example on Fig. $2 B$ and on Video 2). The initial steps (prophase, metaphase, and anaphase) took place as expected, but during telophase, cytokinesis aborted. The cells established an acto-myosin ringlike structure (Fig. $2 B$, panel 3) but no contractile movement could be seen. Ultimately, disappearance of the ring led to the formation of a binuclear hepatocyte (Fig. $2 B$, panel 4). The average length of mitosis was similar during the two types of division (61 $\pm 5 \mathrm{~min}$; from three independent experiments). In particular, the duration of telophase was not reduced by the abortion of cytokinesis. We conclude, therefore, that acytokinesis is the basis of hepatocyte binucleation.

Binuclear Hepatocyte Is a Pivotal Cell for the Genesis of Tetraploid Hepatocytes-We then determined whether binuclear hepatocytes could proceed through a complete subsequent cell cycle. In fact, under certain experimental conditions recent results have demonstrated the existence of a p53-dependent checkpoint control acting in $\mathrm{G}_{1}$ to recognize tetraploid cells and induce their arrest (17-19). For this purpose, we first analyzed whether binuclear hepatocytes were able to progress through S phase. We performed BrdUrd labeling on hepatocytes isolated from 28 days-old male rats (the maximum level of binuclear 


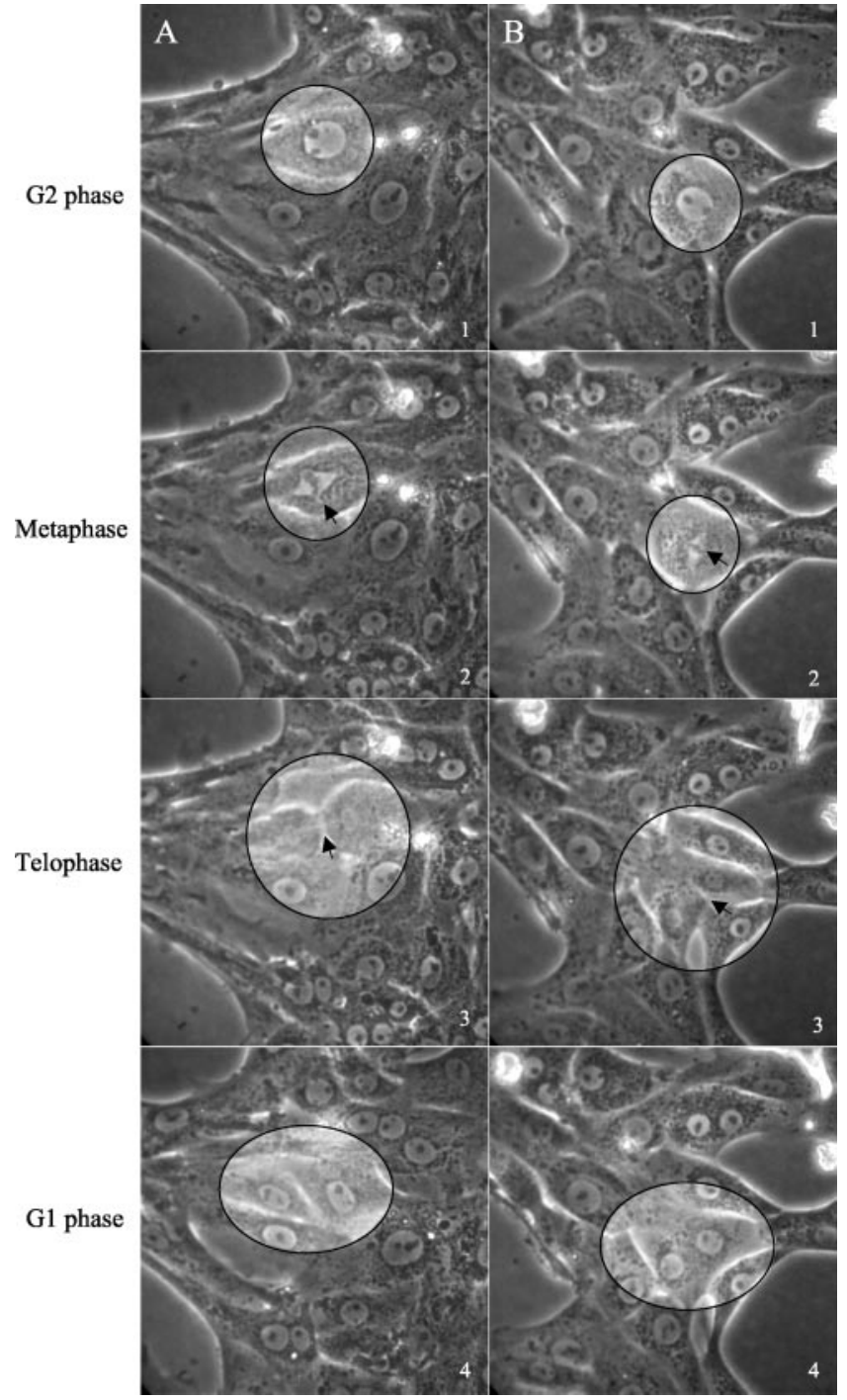

FIG. 2. Genesis of binuclear $2 \times 2 n$ hepatocytes because of the failure of cytokinesis. Hepatocytes were isolated from 24 day-old male rats and cultured in serum-free medium with epidermal growth factor (5 nM), insulin (100 nM), and dexamethasone (25 nM). Epidermal growth factor was added $24 \mathrm{~h}$ after plating. Hepatocytes were mounted on time-lapse videomicroscopy $48 \mathrm{~h}$ after plating. The mitosis of mononuclear $2 \mathrm{n}$ cells was monitored for $24 \mathrm{~h}$. Images are shown at selected time points. $A$, division of a mononuclear $2 \mathrm{n}$ hepatocyte leads to two mononuclear daughter $2 \mathrm{n}$ cells ( $80 \%$ of cases). Arrows indicate the metaphase plate on panel 2 and the contractile ring on panel 3 . B, division of a mononuclear $2 \mathrm{n}$ hepatocyte leads to a binuclear $2 \times 2 \mathrm{n}$ cell (20\% of cases). Arrows indicate the metaphase plate on panel 2 and the deficient contractile ring on panel 3. Complete movies (Video 1 and 2) are available as supplementary information.

cells is found in the liver at this age). Analysis of BrdUrd incorporation revealed that DNA replication occurred in binuclear as well as mononuclear hepatocytes (Fig. 3A); maximum labeling $(35 \%)$ was observed between 48 and $60 \mathrm{~h}$ of culture, which corresponds to the peak of $\mathrm{S}$ phase for the mononuclear $2 \mathrm{n}$ fraction. We next determined whether the absence of the p53-dependent checkpoint could explain the cell cycle progression of binuclear cells. We monitored the level of p53 by Western blot and immunofluorescence on primary hepatocyte cultures (28 day-old male rats) (Fig. $3, B$ and $C$ ). We did not observe any significant changes to the expression of p53 at different times during culture compared with the increasing expression of cyclin E (Fig. 3B). Moreover, p53 was expressed in both mononuclear $2 \mathrm{n}$ and binuclear $2 \times 2 \mathrm{n}$ hepatocytes with a predominant nuclear localization. (Fig. $3 C, 48$ and $60 \mathrm{~h}$ of
A

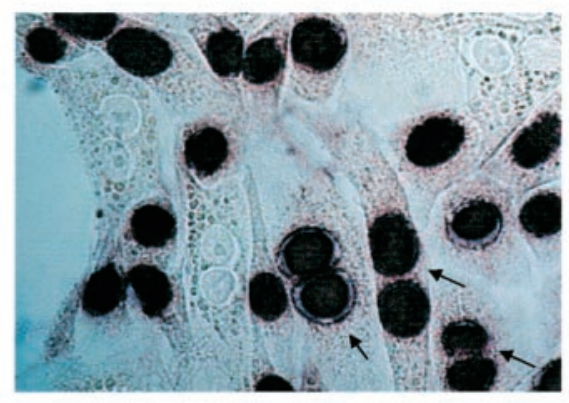

$\begin{array}{llllll}\text { T0 } & \text { T12 } & \text { T24 } & \text { T36 } & \text { T48 } & \text { T60 }\end{array}$

B

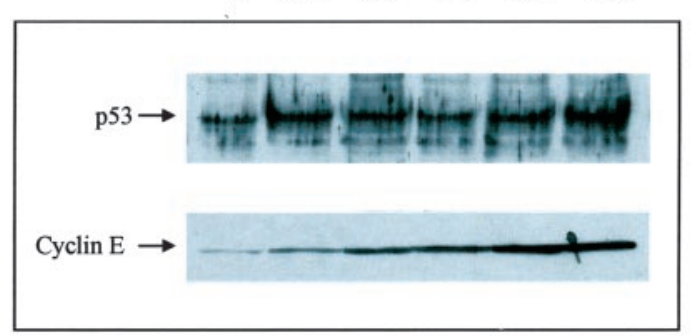

C
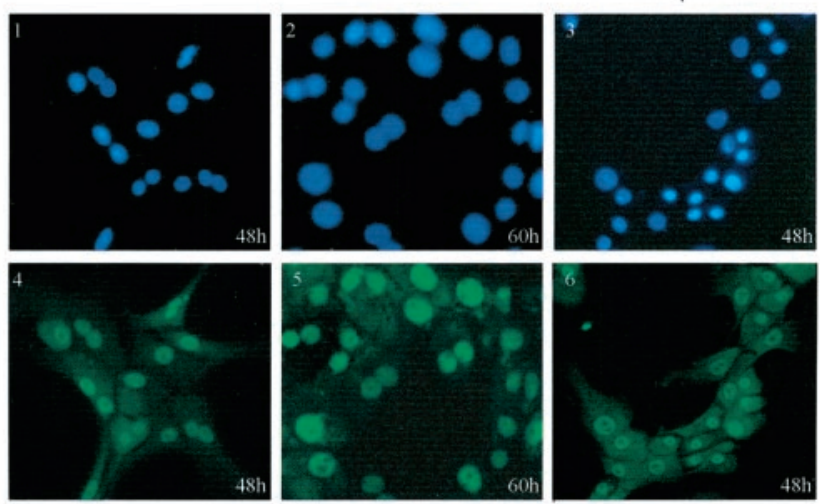

28 days old rat

12 days old rat

FIG. 3. Binuclear hepatocytes progress through $\mathbf{S}$ phase. $A$, hepatocytes were isolated from 28-day-old male rats. The cell cycle progression was evaluated by determining BrdUrd incorporation. Hepatocytes were incubated with BrdUrd for $12 \mathrm{~h}$ and subsequently fixed and labeled. In this experiment, BrdUrd was incorporated between 48 and $60 \mathrm{~h}$ of culture (maximal DNA synthesis). $B$, cell lysates were prepared at different times during a primary culture of hepatocytes isolated from the same rat. The expression of p53 and cyclin E was analyzed by immunoblotting as described under "Experimental Procedures." $C$, p53 protein was detected by immunofluorescence in hepatocytes isolated either from 28-day-old male rats ( 48 and $60 \mathrm{~h}$ of culture; panels $1,2,4$, and 5 ) or from 12-day-old male rats (48 $\mathrm{h}$ of culture; panels 3 and 6). Visualization of DNA by Hoechst staining (panels 1-3) and p53 staining with the antibody FL393 (panels 4-6) is shown. The same expression pattern was observed at different time points during the culture.

culture, panels 1, 2, 4, and 5). Furthermore, we observed the same p53 pattern in hepatocytes isolated from 12 day-old male rats (Fig. $3 C, 48 \mathrm{~h}$ of culture, panels 3 and 6 ). Taken together, these results indicate that p53 was expressed in hepatocytes of different ploidy classes; moreover, its expression did not prevent the cell cycle progression of binuclear hepatocytes.

Thereafter, we monitored the mitosis of binuclear cells using time-lapse videomicroscopy. After $48 \mathrm{~h}$ of culture in four different experiments, 20 binuclear cells were analyzed for up to $24 \mathrm{~h}$. We observed that all of the binuclear cells monitored proceeded identically through mitosis. An example is shown in Fig. 4 and on Video 3. We observed that both nuclei of the binuclear hepatocyte entered mitosis simultaneously. The key step occurred during 


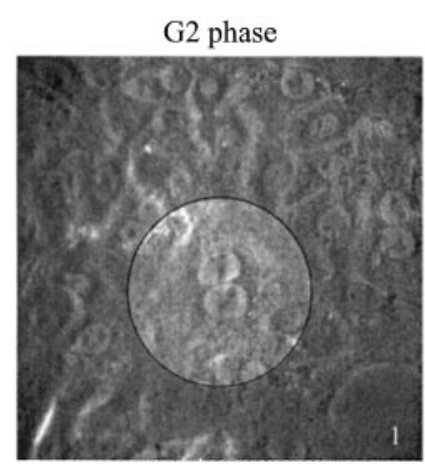

Anaphase-B

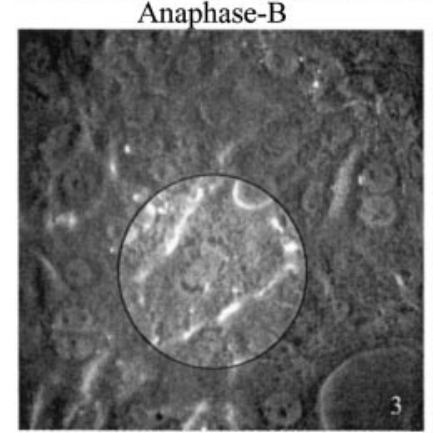

Exit mitosis
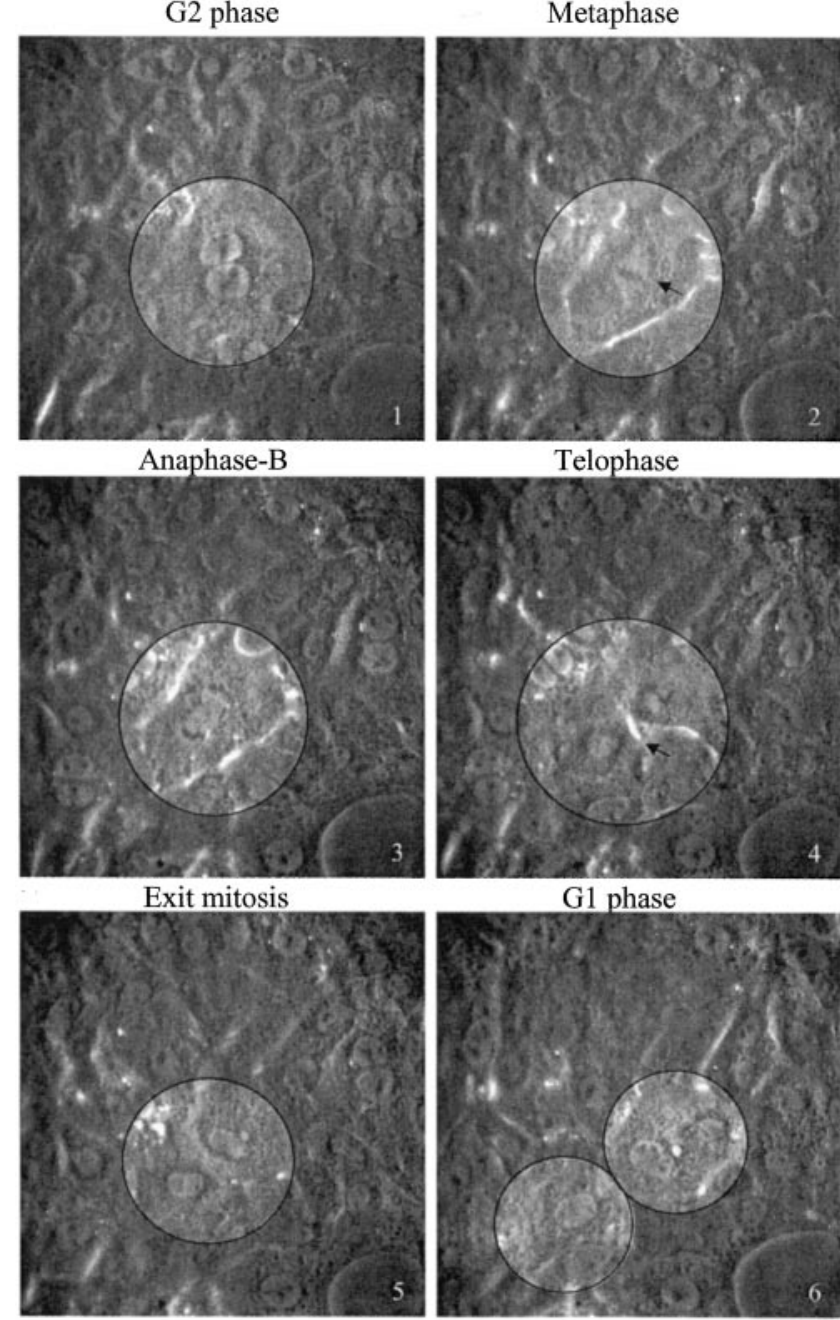

G1 phase

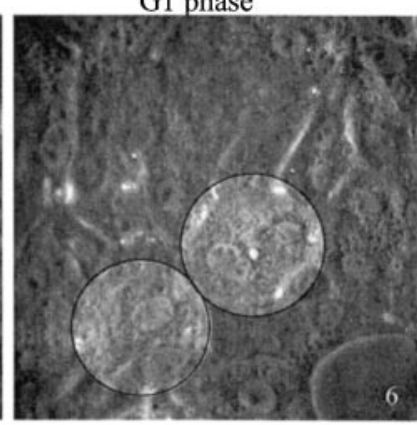

Fig. 4. Outcome of binuclear $2 \times 2$ n cells. Primary hepatocytes from 28 day-old rats were mounted under time-lapse videomicroscopy $48 \mathrm{~h}$ after plating. The mitosis of binuclear $2 \times 2 \mathrm{n}$ cells was monitored over a 24 -h period. Images are shown at selected time points. The division of a binuclear $2 \mathrm{n}$ hepatocyte generated two mononuclear $4 \mathrm{n}$ cells. Arrows indicate the two-pole spindle and metaphase plate (panel 2 ) and the contractile ring (panel 3). The complete movie (Video 3) is available as supplementary information.

metaphase; a bipolar spindle was formed, leading to the alignment of all chromosomes along the same plate (Fig. 4, panel 2). Thereafter, during anaphase sister chromatids separated and migrated toward the two opposing poles as expected (Fig. 4, panel 3). Cytokinesis occurred correctly at the end of telophase (Fig. 4, panel 4). Ultimately, this gave rise to two mononuclear $4 \mathrm{n}$ daughter hepatocytes (Fig. 4, panels 5 and 6). Taken together, these experiments show that binuclear hepatocyte is the pivotal cell giving rise to mononuclear $4 \mathrm{n}$ progeny.

Centrosome Traffic during the Division of Binuclear Hepatocytes - To explain the formation of a unique bipolar spindle during the division of binuclear hepatocytes, we studied centrosome duplication and separation in these cells. During the $\mathrm{G}_{1}$ phase, in a diploid mammalian cell the centrosome comprises a pair of centrioles connected via a proteinaceous linkage (20). The centrosome is duplicated during $\mathrm{S}$ phase when a procentriole buds from each parental centriole. During prophase, the centriolar linkage is disrupted, and the two centrosomes separate and migrate apart to form the bipolar spindle. During our study, we scored the number of centrosomes at different stages of the cell cycle to characterize bipolar spindle formation in binuclear hepatocytes. Using immunofluorescence analysis on primary cell cultures, we showed that a binuclear hepatocyte displayed two centrosomes during $G_{1}$ phase $(2 n$ DNA content per nucleus) and four centrosomes during $G_{2}$ phase (4n DNA content per nucleus) (Fig. 5A). Thus a binuclear hepatocyte inherited two parental centrosomes from mononuclear $2 \mathrm{n}$ cells, which duplicated. We then studied their movement during mitosis. The nuclei entered prophase simultaneously (Fig. 5B). At this point, the four centrosomes moved apart and, at metaphase, clustered in pairs at opposite poles of the cell (Fig. 5B). During telophase, centrosome clustering was maintained (Fig. 5B). Finally, leaving mitosis, the two daughter mononuclear $4 \mathrm{n}$ cells will inherit two centrosomes from the binuclear $2 \times 2$ n hepatocyte. This phenomenon was always observed. At last, we determined whether each centrosome was capable of nucleating microtubules. During prophase, the four centrosomes of binuclear hepatocytes nucleated microtubule asters like the two centrosomes of a mononuclear cell (Fig. $5 \mathrm{C}$ ) and therefore participated in the formation of the bipolar spindle. We were therefore able to demonstrate that, in the binuclear hepatocyte, centrosome clustering appeared to constitute a key event during formation of the bipolar spindle, giving rise solely to mononuclear $4 \mathrm{n}$ progeny.

\section{DISCUSSION}

In this report, we demonstrate that liver cell polyploidization is an original physiological process passing through a binucleation step. A proportion of mononucleated $2 \mathrm{n}$ hepatocytes aborted cytokinesis and thus generated a binuclear hepatocyte $2 \times 2$ n. This binuclear cell was able to pass through a new cell cycle and subsequently divide into two mononuclear $4 \mathrm{n}$ cells. Moreover, we showed that the clustering of centrosomes during mitosis was a key step in the genesis of mononuclear $4 n$ hepatocytes.

First of all, we were interested in characterizing changes to hepatocyte polyploidization during liver growth in vivo. In fact, only ex vivo studies utilizing methods such as karyometry (3), cytophotometry (21), flow cytometry (22), and fluorescence microscopy (23) have so far described this phenomenon after cell isolation and purification. In this study, we developed a method that accurately distinguished mononuclear and binuclear cells and measured the DNA content of each nucleus in tissue sections. Our methodology provides the first direct assessment of hepatocyte ploidy status during liver growth and, interestingly, the results of previous ex vivo studies were in line with ours. We demonstrated in vivo during post-natal development that the liver is almost solely made up of diploid hepatocytes for the first 22 days; thereafter, between the ages of 22 and 28 days the decline of this population is strictly correlated with the appearance of the binuclear population. These results strongly suggest that the mononuclear $2 \mathrm{n}$ hepatocyte is the precursor of the binuclear hepatocyte. Moreover, we observed that the mononuclear $4 \mathrm{n}$ population appeared 30 days after birth, by which stage the binuclear population was slowly declining. These observations suggest that a binuclear status may constitute an intermediate step prior to the generation of mononuclear $4 \mathrm{n}$ hepatocytes.

To analyze more precisely the cellular mechanisms involved in hepatocyte polyploidization, we followed the division of cells during primary culture. We directly demonstrated that mononuclear $2 \mathrm{n}$ hepatocytes were the precursors of binuclear $2 \times 2 \mathrm{n}$ cells using time-lapse videomicroscopy. We showed that $20 \%$ of mononuclear $2 \mathrm{n}$ hepatocytes abort cytokinesis; no movement of the contractile ring was observed, and its disappearance led to the genesis of a binuclear cell. This report therefore provides the first direct evidence that acytokinesis forms the basis for hepatocyte binucleation. Previous studies (based on other cell types) had described the binucleation processes as a result of 
A

FIG. 5. Centrosomes of binuclear hepatocytes duplicated during $S$ phase and by their specific migration induced the formation of a bipolar spindle. $A$, hepatocytes were cultured for $24 \mathrm{~h}\left(\mathrm{G}_{1}\right.$ phase $)$ or $52 \mathrm{~h}\left(\mathrm{G}_{2}\right.$ phase $)$ and then fixed for immunofluorescence microscopy. Double staining was performed using specific antibody against $\gamma$-tubulin (green) to reveal centrosomes, followed by counterstaining with Hoechst coloration (blue) for DNA. DNA content was evaluated by recording Hoechst fluorescence in the nuclei of binuclear cells. The peak DNA content of cells with four centrosomes $(2 \times 4 n)$ was positioned at twice the value of one of the cells with two centrosomes $(2 \times 2 \mathrm{n}) . B$ and $C$, hepatocytes were cultured for $60 \mathrm{~h}$. At this stage of the culture, the higher mitotic index was detected (data not shown). Cells were permeabilized and fixed in order to observe the localization of centrosomes and the mitotic spindle. $B$, anti- $\gamma$-tubulin antibody was used to visualize the centrosome (green) and, Hoechst was used to visualize DNA (blue). $C$, anti- $\beta$-tubulin was used to visualize microtubule asters (green), and Hoechst was used to visualize DNA (blue).
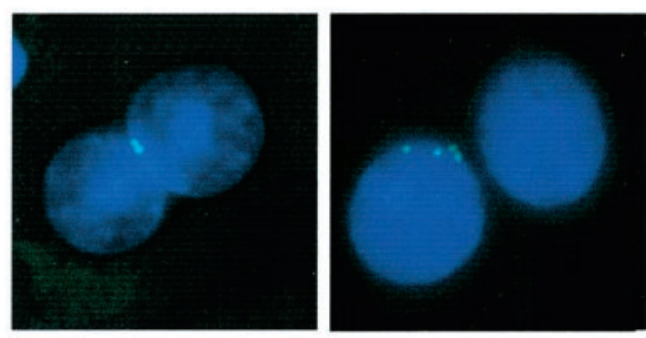

G1 phase
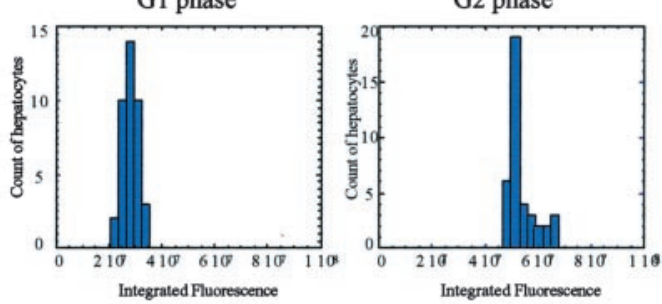

B

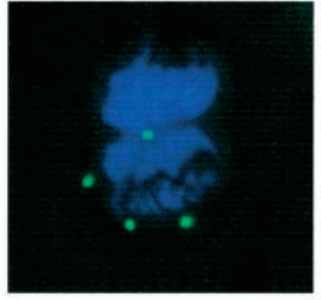

Prophase

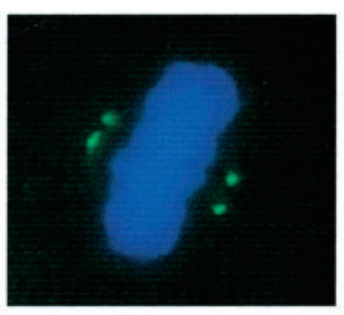

Metaphase

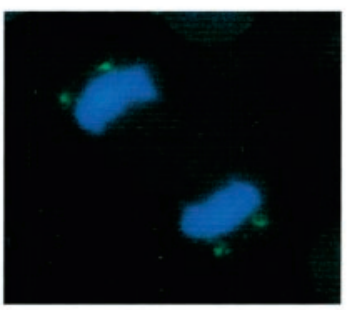

Telophase

C

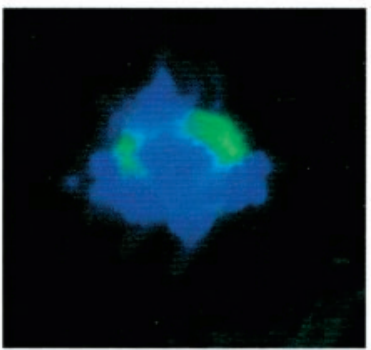

Mononuclear $2 \mathrm{n}$ hepatocyte

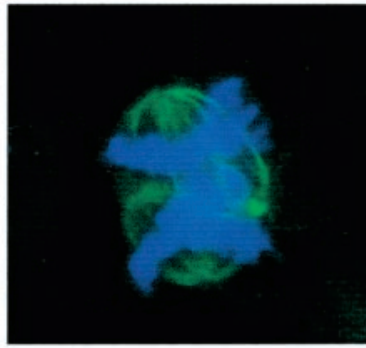

Binuclear $2 \times 2 \mathrm{n}$ hepatocyte exit from mitosis because of either the absence or abortion of cytokinesis (18, 24-33). However, this process has been observed following antibody suppression or overexpression or the mutagenesis of several proteins involved in cell cleavage. These proteins include passenger proteins such as INCENP (24) and survivin (25); protein kinases such as polo-like kinase and aurora A and B (18, 26, 27); small G-proteins and their regulators such as citron kinase, MgcRacGap, and Vav3 (28-30); and microtubule motor proteins such as CENP-E (31), MKLP1 (32), and PRC1 (33). Our study offers an experimental model to investigate whether one or several of these proteins are also involved in the physiological hepatocyte binucleation process. In this context, it is interesting to note that a recent study suggested that citron kinase is not implicated in the binucleation process during post-natal liver development (34).

Furthermore, we have shown that binuclear hepatocytes divide into two mononuclear $4 \mathrm{n}$ hepatocytes. Binuclear hepatocytes were able to progress through $\mathrm{S}$ phase in primary culture, and this observation was not due to the culture conditions, since binuclear hepatocytes were also BrdUrd-labeled in vivo during liver growth (data not shown). Intriguingly, recent studies in other cell types (for example HeLa cells and embryo fibroblasts) have shown that tetraploidy, induced by an inap- propriate exit of cells from mitosis following the failure of spindle assembly, chromosome segregation, or cytokinesis, causes all cells to arrest in $\mathrm{G}_{1}(17,18)$. In that model, the function of the p53 protein was required to impose $G_{1}$ arrest in response to tetraploidization. Its inactivation caused a failure to arrest at this $\mathrm{G}_{1}$ checkpoint, and tetraploid cells then rapidly progressed to aneuploidy. In these cells, amplified numbers of centrosomes and their abnormal clustering led to the formation of multipolar mitotic spindles (19). Contrastingly, in our experimental system p53 was expressed in all binuclear and mononuclear hepatocytes. Thus, our observations demonstrate that $\mathrm{G}_{1}$ checkpoint control by p53 is not activated by physiological acytokinesis in hepatocytes. Three studies in p53-deficient mice have addressed the implication of p53 in hepatocyte ploidization $(13,21,35)$. Although discrepant results were obtained in one of these studies, the other two showed that the p53 genotype (p53+/+, p53 +, p53-/-) did not influence hepatocyte polyploidization $(13,35)$. Our study therefore provides direct support for this hypothesis. It will be interesting in the future to search for other potential checkpoints, including (in particular) the retinoblastoma $(\mathrm{Rb})$ pocket protein family (19).

Following the mitosis of binuclear hepatocytes, we established that $100 \%$ of these cells formed a bipolar spindle, leading 
to the alignment of all chromosomes on one metaphase plate, a prerequisite for correct chromosome segregation, thus ensuring the tetraploidy status of progeny cells. Interestingly, we found that the two centrosomes of a $\mathrm{G}_{1}$ binuclear hepatocyte duplicated during $\mathrm{S}$ phase and then associated in pairs at metaphase at the two opposite poles of the cell. Formation of the bipolar spindle with two active centrosomes at each pole may be necessary to ensure spindle stability and correct segregation of the $8 \mathrm{n}$ DNA content. How the centrosomes migrate in pairs to the two opposite poles of the cell is still to be determined. In diploid cells, at $\mathrm{G}_{2} / \mathrm{M}$ transition the dynamic structure linking parental centrioles is disrupted, and the two centrosomes then move apart to form the mitotic spindle (36). In binuclear hepatocytes, the lack of disruption to this structure may prevent separation of the pair of centrosomes and lead to their specific positioning at the two poles of the cell in metaphase.

In conclusion, the hepatocyte constitutes a particularly interesting model of a ploidy process leading first to binuclear cells, which then evolve into mononuclear tetraploid cells. Further work will make it possible to decode the molecular mechanisms controlling hepatocyte tetraploidization and the prevention of aneuploidy.

Acknowledgments-We thank F. Demaugre, D. Kremsdorf, and N. Ferry for helpful discussions and D. Euphrasie and G. Pivert for technical assistance. We also thank the imaging facility at the Jacques Monod Institute (Paris, France) for live cell videomicroscopy analysis.

\section{REFERENCES}

1. Ravid, K., Lu, J., Zimmet, J. M., and Jones, M. R. (2002) J. Cell. Physiol. 190 $7-20$

2. Sigal, S. H., Rajvanshi, P., Gorla, G. R., Sokhi, R. P., Saxena, R., Gebhard, D. R., Jr., Reid, L. M., and Gupta, S. (1999) Am. J. Physiol. 276, G1260-G1272

3. Nadal, C., and Zajdela, F. (1967) Exp. Cell Res. 48, 518-528

4. Saeter, G., Schwarze, P. E., Nesland, J. M., Juul, N., Pettersen, E. O., and Seglen, P. O. (1988) Carcinogenesis 9, 939-945

5. Wheatley, D. N. (1972) Exp. Cell Res. 74, 455-465

6. Kudryavtsev, B. N., Kudryavtseva, M. V., Sakuta, G. A., and Stein, G. I. (1993) Virchows Arch. B Cell Pathol. 64, 387-393

7. Seglen, P. O. (1997) Cell Biol. Toxicol. 13, 301-315

8. Galitski, T., Saldanha, A. J., Styles, C. A., Lander, E. S., and Fink, G. R. (1999) Science 285, 251-254
9. Schwarze, P. E., Pettersen, E. O., Shoaib, M. C., and Seglen, P. O. (1984) Carcinogenesis 5, 1267-1275

10. Gomez-Lechon, M. J., Barbera, E., Gil, R., and Baguena, J. (1981) Cell. Mol. Biol. 27, 695-701

11. Wu, H., Wade, M., Krall, L., Grisham, J., Xiong, J., and Van Dyke, T. (1996) Genes Dev. 10, 245-260

12. Minamishima, Y. A., and Nakayama, K. (2002) Cancer Res. 62, 995-999

13. Nunez, F., Chipchase, M. D., Clarke, A. R., and Melton, D. W. (2000) FASEB J. 14, 1073-1082

14. Chassoux, D., Franchi, J., Cao, T. T., and Debey, P. (1999) Anal. Quant. Cytol. Histol. 21, 489-497

15. McIntyre, M., Desdouets, C., Senamaud-Beaufort, C., Laurent-Winter, C., Lamas, E., and Brechot, C. (1999) Oncogene 18, 4577-4585

16. Sigal, S. H., Gupta, S., Gebhard, D. F., Jr., Holst, P., Neufeld, D., and Reid, L. M. (1995) Differentiation 59, 35-42

17. Andreassen, P. R., Lohez, O. D., Lacroix, F. B., and Margolis, R. L. (2001) Mol. Biol. Cell 12, 1315-1328

18. Meraldi, P., Honda, R., and Nigg, E. A. (2002) EMBO J. 21, 483-492

19. Borel, F., Lohez, O. D., Lacroix, F. B., and Margolis, R. L. (2002) Proc. Natl. Acad. Sci. U. S. A. 99, 9819-9824

20. Lange, B. M. (2002) Curr. Opin. Cell Biol. 14, 35-43

21. Yin, L., Ghebranious, N., Chakraborty, S., Sheehan, C. E., Ilic, Z., and Sell, S. (1998) Hepatology 27, 73-80

22. Mossin, L., Blankson, H., Huitfeldt, H., and Seglen, P. O. (1994) Exp. Cell Res. 214, $551-560$

23. Martin, N. C., McCullough, C. T., Bush, P. G., Sharp, L., Hall, A. C., and Harrison, D. J. (2002) J. Cell. Physiol. 191, 138-144

24. Mackay, A. M., Ainsztein, A. M., Eckley, D. M., and Earnshaw, W. C. (1998) J. Cell Biol. 140, 991-1002

25. Skoufias, D. A., Mollinari, C., Lacroix, F. B., and Margolis, R. L. (2000) J. Cell Biol. 151, 1575-1582

26. Lee, K. S., Yuan, Y. L., Kuriyama, R., and Erikson, R. L. (1995) Mol. Cell. Biol. 15, 7143-7151

27. Terada, Y., Tatsuka, M., Susuki, F., Yasuda, Y., Fujita, S., and Otsu, M. (1998) EMBO 3, 667-676

28. Madaule, P., Eda, M., Watanabe, N., Fujisawa, K., Matsuoka, T., Bito, H., Ishizaki, T., and Narumiya, S. (1998) Nature 394, 491-494

29. Hirose, K., Kawashima, T., Iwamoto, I., Nosaka, T., and Kitamura, T. (2001) J. Biol. Chem. 276, 5821-5828

30. Fujikawa, K., Inoue, Y., Sakai, M., Koyama, Y., Nishi, S., Funada, R., Alt, F. W., and Swat, W. (2002) Proc. Natl. Acad. Sci. U. S. A. 99, 4313-4318

31. Martineau-Thuillier, S., Andreassen, P. R., and Margolis, R. L. (1998) Chromosoma 107, 461-470

32. Nislow, C., Lombillo, V. A., Kuriyama, R., and McIntosh, J. R. (1992) Nature 359, 543-547

33. Mollinari, C., Kleman, J. P., Jiang, W., Schoehn, G., Hunter, T., and Margolis, R. L. (2002) J. Cell Biol. 157, 1175-1186

34. Liu, H., Di Cunto, F., Imarisio, S., and Reid, L. M. (2003) J. Biol. Chem. 278 , $2541-2548$

35. Bellamy, C. O., Clarke, A. R., Wyllie, A. H., and Harrison, D. J. (1997) FASEB J. 11, 591-599

36. Mayor, T., Stierhof, Y. D., Tanaka, K., Fry, A. M., and Nigg, E. A. (2000) J. Cell Biol. 151, 837-846 
Liver Cell Polyploidization: A Pivotal Role for Binuclear Hepatocytes

Jacques-Emmanuel Guidotti, Olivier Brégerie, Aude Robert, Pascale Debey, Christian Brechot and Chantal Desdouets

J. Biol. Chem. 2003, 278:19095-19101.

doi: 10.1074/jbc.M300982200 originally published online March 7, 2003

Access the most updated version of this article at doi: $10.1074 / \mathrm{jbc}$.M300982200

Alerts:

- When this article is cited

- When a correction for this article is posted

Click here to choose from all of JBC's e-mail alerts

This article cites 36 references, 16 of which can be accessed free at http://www.jbc.org/content/278/21/19095.full.html\#ref-list-1 